\title{
Evaluation of Galleria mellonella larvae as an in vivo model for assessing the relative toxicity of food preservative agents
}

\author{
Ronan Maguire • Orla Duggan • Kevin Kavanagh
}

Received: 5 February 2016/Accepted: 18 April 2016/Published online: 27 April 2016

C) Springer Science+Business Media Dordrecht 2016

\begin{abstract}
Larvae of Galleria mellonella are widely used for evaluating the virulence of microbial pathogens and for measuring the efficacy of anti-microbial agents and produce results comparable to those that can be obtained using mammals. In this work, the suitability of using $G$. mellonella larvae to measure the relative toxicity of a variety of food preservatives was evaluated. The response of larvae to eight commonly used food preservatives (potassium nitrate, potassium nitrite, potassium sorbate, sodium benzoate, sodium nitrate, sodium chloride, sodium nitrite and sodium acetate) administered by feeding or by intra-haemocoel injection was measured. A significant correlation between the $\mathrm{LD}_{50}$ $\left(R^{2}=0.8766, p=0.0006\right)$ and $\operatorname{LD}_{80}\left(R^{2}=0.7629\right.$, $p=0.0046)$ values obtained due to oral or intrahaemocoel administration of compounds was established. The response of HEp-2 cells to the food preservatives was determined, and a significant correlation $\left(R^{2}=0.7217, p=0.0076\right)$ between the $\mathrm{LD}_{50}$ values of the compounds administered by feeding in larvae with the $\mathrm{IC}_{50}$ values of the compounds in HEp-2 cells was established. A strong correlation between the $\mathrm{LD}_{50}$ values of the eight food preservatives in G. mellonella larvae and rats $\left(R^{2}=0.6506, p=0.0156\right)$ was demonstrated. The results presented here indicate that G. mellonella larvae may be used as a model to evaluate
\end{abstract}

R. Maguire $\cdot$ O. Duggan $\cdot$ K. Kavanagh $(\bowtie)$

Department of Biology, Maynooth University, Maynooth, Co.

Kildare, Ireland

e-mail: kevin.kavanagh@nuim.ie the relative toxicity of food preservatives, and the results show a strong positive correlation to those obtained using established cell culture and mammalian models.

Keywords Food preservative - Galleria - Insect . In vivo $\cdot$ Toxicity
Abbreviations
PNi Potassium nitrite
$\mathrm{SNi}$ Sodium nitrite
SB Sodium benzoate
PS Potassium sorbate
SA Sodium acetate
$\mathrm{SNa}$ Sodium nitrate
$\mathrm{PNa}$ Potassium nitrate
SC Sodium chloride
PBS Phosphate buffered saline

\section{Introduction}

The insect immune response consists of inter-connected humoral and cellular components and demonstrates many similarities to the innate immune response of mammals (Kavanagh and Reeves 2004). As a consequence of these similarities, insects have been utilized as model systems for studying the virulence of microbial pathogens and for assessing the efficacy of anti-microbial drugs and give results comparable to those that can be obtained using mammals (Desbois and Coote 2012; Mylonakis et al. 2005). A number of insect models are now established 
for these purposes including Drosophila melanogaster (Chamilos et al. 2011; Lionakis and Kontoyiannis 2005), Galleria mellonella larvae (Cook and McArthur 2013; Fallon et al. 2012; Rowan et al. 2009) and Bombyx mori (Hamamoto et al. 2009). Insects have also been utilized to measure the relative toxicity of novel antimicrobial agents (Desbois and Coote 2012) and the toxicity of food additives (Grunwald et al. 2013; Sarikaya and Cakir 2005). Another advantage of insects as an in vivo model system is that they possess a lower pain perception than vertebrates, and there are no ethical or legal issues surrounding their use.

G. mellonella larvae offer many advantages as an in vivo screening system, including the ability to survive temperatures in excess of $30{ }^{\circ} \mathrm{C}$ and the possibility of administering accurate doses of test compounds via three routes (topical application, feeding or intra-haemocoel injection). As a consequence, G. mellonella larvae are now widely used for screening microbial pathogens (Fallon et al. 2011; Fuch et al. 2010) and for assessing in vivo activity of novel anti-microbial agents (Kelly and Kavanagh 2011). Larvae of $G$. mellonella have also been utilized to study the pathogenicity of Listeria, which produces neural pathologies in larvae similar to those evident in humans (Mukherjee et al. 2013).

The insect and mammalian gastrointestinal tracts share many histological, anatomical and physiological structural functions. The microvilli in the midgut of G. mellonella larvae contain microbes that resemble those found in the intestinal microvilli of mammals (Mukherjee et al. 2013). The insect fat body is an organ that functions in metabolism and is similar to the liver of mammals (Buyukguzel et al. 2013). A number of cytochrome P450 and sulfo-, glutathione- or glucoseconjugation enzymes, which are involved in drug detoxification, are located in the fat body. Haemolymph, which circulates in the insect body cavity (haemocoel), is a functional analogue of mammalian blood; however, it does not transport gases. The haemolymph contains haemocytes which function in transportation and in the immune defence of the insect (Kavanagh and Reeves 2004). The humoral immune response results in the process of melanization and the production of a range of anti-microbial peptides to immobilize and kill an invading pathogen respectively.

A wide range of mammalian cell lines have been utilized for assessing the in vitro toxicity of compounds (Fotakis and Timbrell 2006). Human epithelial type 2 (HEp-2) cells were originally derived from a human laryngeal carcinoma and have been utilized to determine the efficacy of anti-cancer drugs (Rossi et al. 2003), the cytotoxicity of nanoparticles (Ahamed et al. 2015) and the toxicity of food additives (Angelis et al. 1994).

Preservatives are widely used in the food industry to inhibit microbial growth or prevent chemical changes that would adversely affect the quality of foods. Food preservatives such as sodium chloride and sodium acetate (E262) belong to a group of food additives composed of anti-microbials, anti-oxidants and antibrowning agents (Carocho et al. 2014). The antimicrobial agent potassium sorbate (E2020) can be employed in foods with higher $\mathrm{pH}$ values, whereas another sodium benzoate (E211) can be used with acidic foods. Potassium/sodium nitrate (E252/E251) and potassium/sodium nitrite (E249/E250) are used for curing in the meat industry. Nitrites are considered the only food preservative that inhibits the production of the botulinum toxin, thereby justifying their use in a benefit/risk scale in the food industry. The acute toxicity of a compound intended for use as a food additive or preservative is measured as the calculated dose of a substance that is expected to cause the death of $50 \%$ of a defined experimental animal population and is known as the lethal dose $50\left(\mathrm{LD}_{50}\right)$ value.

The aims of the work presented here were to evaluate the potential of using $G$. mellonella larvae as a rapid in vivo screening system for assessing the relative toxicity of a range of widely used food preservatives and to compare the relative toxicity of the compounds to that obtained using a cultured human cell line and rats.

\section{Materials and methods}

\section{Chemicals}

All chemicals and reagents were of the highest purity and quality and were purchased from Sigma Aldrich Co. Ltd., Dorset, UK, unless otherwise stated.

\section{G. mellonella larvae}

Larvae of the sixth developmental stage of $G$. mellonella were obtained from the Meal Worm Company (Sheffield, England). Larvae were stored in wood shavings in the dark at $15^{\circ} \mathrm{C}$ prior to use. Larvae that weighed 0.22 $\pm 0.03 \mathrm{~g}$ were used within 2 weeks of receipt. For each treatment, ten healthy larvae were placed in sterile $9-\mathrm{cm}$ 
petri dishes lined with Whatman filter paper and containing some wood shavings.

G. mellonella intra-haemocoel inoculation and force-feeding

The test compounds were dissolved and diluted to the required concentrations. Samples $(20 \mu \mathrm{l})$ were injected into the G. mellonella haemocoel through the last left pro-leg using a Myjector syringe (Terumo Europe) as described previously (Cotter et al. 2000). In order to administer compounds by the feeding route, a blunted Myjector syringe was gently inserted into the mouth of larvae to force-feed $20 \mu \mathrm{l}$ of each solution (Mukherjee et al. 2013). The inoculated larvae were incubated at $30{ }^{\circ} \mathrm{C}$ for $48 \mathrm{~h}$. For the assessment of larval viability, larvae were gently probed with a blunt-ended needle and if no response was observed, the larvae were considered to be dead. The $\mathrm{LD}_{50}$ and $\mathrm{LD}_{80}$ values were defined as the concentration of compound that resulted in 50 or $80 \%$ larval mortality respectively after $48 \mathrm{~h}$.

Mammalian cell culture

HEp-2 cells were grown in $25 \mathrm{~cm}^{2}$ tissue culture flasks (Sarstedt) containing Eagle's minimum essential medium supplemented with $5 \%(v / v)$ foetal calf serum and $2 \%(v / v)$ glutamine and incubated at $37{ }^{\circ} \mathrm{C}$ in a humidified atmosphere containing $5 \% \mathrm{CO}_{2}$. Confluent cells were trypsinized, enumerated and used to seed 96-well plates (Corning Incorporated $\operatorname{Costar}^{\circledR}$ ) at a density of $1 \times 10^{4}$ cells/well in $100 \mu \mathrm{l}$ minimum essential medium (MEM) culture medium. After $24 \mathrm{~h}$, incubation cells were exposed to different concentrations of the test compounds dissolved in MEM. The plates were incubated at $37{ }^{\circ} \mathrm{C}$ and $5 \% \mathrm{CO}_{2}$ for 7 days prior to the quantification of cell growth.

Quantifying effect of food preservatives on cell growth

The effect of the test compounds on the growth of HEp2 cells was determined using the acid phosphatase assay (Yang et al. 1996). Following incubation, medium containing test compounds was removed from each well, and the attached cells were washed with PBS. To each well, $100 \mu \mathrm{l}$ of buffer containing $0.1 \mathrm{M}$ sodium acetate (pH 5.0), $0.1 \%$ Triton X-100 and $5 \mathrm{mM} p$-nitrophenyl phosphate was added, and the plates were incubated at $37^{\circ} \mathrm{C}$ and $5 \% \mathrm{CO}_{2}$ for $2 \mathrm{~h}$. The reaction was stopped with the addition of $5 \mu \mathrm{l}$ of $1 \mathrm{M} \mathrm{NaOH}$, and colour development was assayed at $405 \mathrm{~nm}$, using a microplate reader (Boi-Tec ${ }^{\circledR}$ Synergy HT). The percentage growth of HEp-2 cells in the presence of food additives was determined. The $\mathrm{IC}_{50}$ was defined as the concentration of agent that inhibited growth of HEp-2 cells by $50 \%$ over the period of the experiment.

Statistical analysis

All assays were performed on three independent occasions. GraphPad software was used to generate fifth-order polynomial regression lines from larval viability data to determine $\mathrm{LD}_{50}$ and $\mathrm{LD}_{80}$ values. Results are expressed as the mean $\pm \mathrm{SE}$ and were compared by $t$ test, using GraphPad. Differences were considered significant at $p<0.05$.

\section{Results}

Assessment of effect of food preservative agents on G. mellonella

G. mellonella larvae were administered the food preservative agents by force-feeding or by intra-haemocoel injection as described, and the $\mathrm{LD}_{50}$ and $\mathrm{LD}_{80}$ values of each compound were determined (Figs. 1 and 2). The relative toxicity of each compound in larvae was greatest when administered by intra-haemocoel injection compared to the feeding route. For example larvae administered potassium nitrite by intra-haemocoel injection (Fig. 2) showed an $\mathrm{LD}_{50}$ value of $2 \times 10^{-6} \mathrm{M}$, compared to an $\mathrm{LD}_{50}$ value of $4 \times 10^{-6} \mathrm{M}$ when larvae were force-fed the compound. Larvae administered sodium benzoate into the haemocoel showed an $\mathrm{LD}_{50}$ value of $4 \times 10^{-6} \mathrm{M}$, compared to an $\mathrm{LD}_{50}$ value of $9 \times 10^{-6} \mathrm{M}$ in larvae that were force-fed with the compound. Larvae administered compounds by the intrahaemocoel route also showed elevated levels of melanization compared to those administered similar concentrations of compound by feeding (data not presented).

A strong correlation between the $\mathrm{LD}_{50}$ and $\mathrm{LD}_{80}$ values for each compound in larvae due to feeding or intra-haemocoel injection was established (Fig. 3). The results show an $R^{2}$ value of $0.8766(p=0.0006)$ between the $\mathrm{LD}_{50}$ values and an $R^{2}$ value of $0.7629(p=0.0046)$ between the $\mathrm{LD}_{80}$ values obtained due to feeding and intra-haemocoel administration respectively. 
Fig. 1 Survival (\%) of Galleria mellonella larvae following feeding with different concentrations of food preservatives. Larvae $(n=10)$ were administered compounds by feeding. All values are the mean \pm SE of three independent determinations

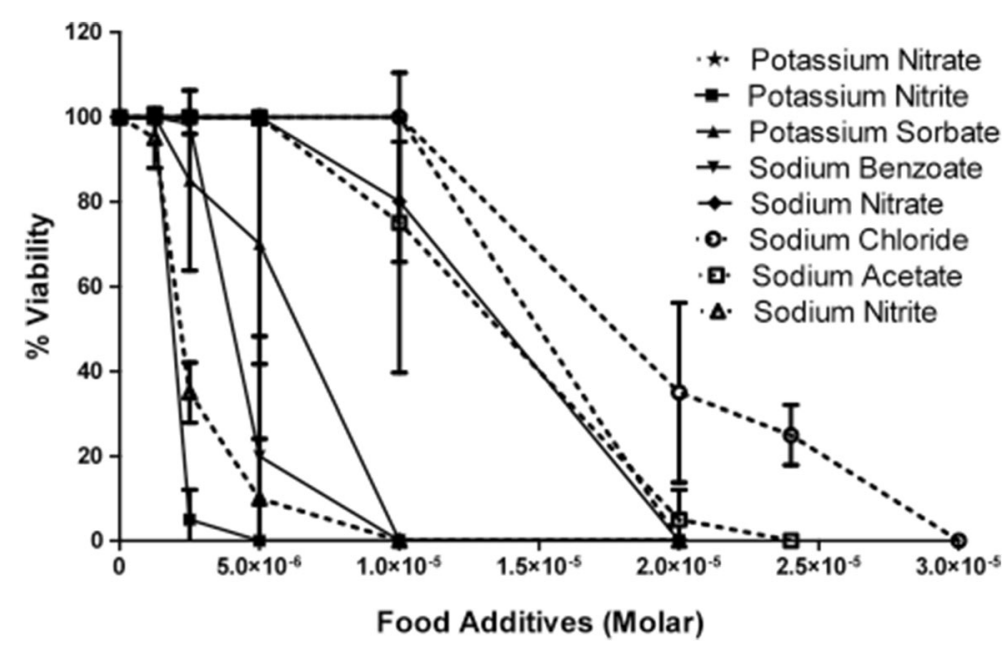

Response of HEp-2 cells to food preservative compounds

HEp-2 cells were exposed to different concentrations of the food preservatives as described, and the effect on growth after 7 days of incubation was assessed using the acid phosphatase assay. Higher concentrations of the compounds reduced growth of the HEp-2 cells (Fig. 4). For example exposure to $1.0 \times 10^{-6} \mathrm{M}$ sodium nitrate reduced growth by over $95 \%$. The $\mathrm{IC}_{50}$ and $\mathrm{IC}_{80}$ values for each compound in HEp-2 cells were determined. The relative toxicity of some compounds when tested against HEp-2 cells was similar to the toxicity observed in G. mellonella. For example potassium nitrite and sodium nitrite were the two most toxic food preservatives in both model systems, whereas sodium chloride was the least toxic compound in both systems.
An $R^{2}$ value of $0.7666(p=0.0076)$ and 0.5032 $(p=0.0488)$ was obtained by plotting the $\mathrm{LD}_{50}$ value for each compound obtained via force-feeding larvae or by intra-haemocoel challenge respectively, with the $\mathrm{IC}_{50}$ value obtained using HEp-2 cells (Fig. 5a, b).

Correlation between response of larvae and rats to food preservative compounds

$\mathrm{LD}_{50}$ values for compounds in rats were previously recorded to be as follows: potassium nitrite $200 \mathrm{mg} / \mathrm{kg}$, sodium nitrite $180 \mathrm{mg} / \mathrm{kg}$, sodium benzoate $4070 \mathrm{mg} / \mathrm{kg}$, potassium sorbate $4340 \mathrm{mg} / \mathrm{kg}$, sodium acetate $3530 \mathrm{mg} / \mathrm{kg}$, sodium nitrate $1267 \mathrm{mg} / \mathrm{kg}$, potassium nitrate $3750 \mathrm{mg} / \mathrm{kg}$ and sodium chloride $3000 \mathrm{mg} / \mathrm{kg}$ (Chemistry 2016; Pfizer 2007; Scholar 2009). The LD $_{50}$ values of each food preservative as determined in rats by
Fig. 2 Survival (\%) of Galleria mellonella larvae following administration of food preservatives by intra-haemocoel injection. Larvae $(n=10)$ were administered compounds by intra-haemocoel injection. All values are the mean $\pm \mathrm{SE}$ of three independent determinations

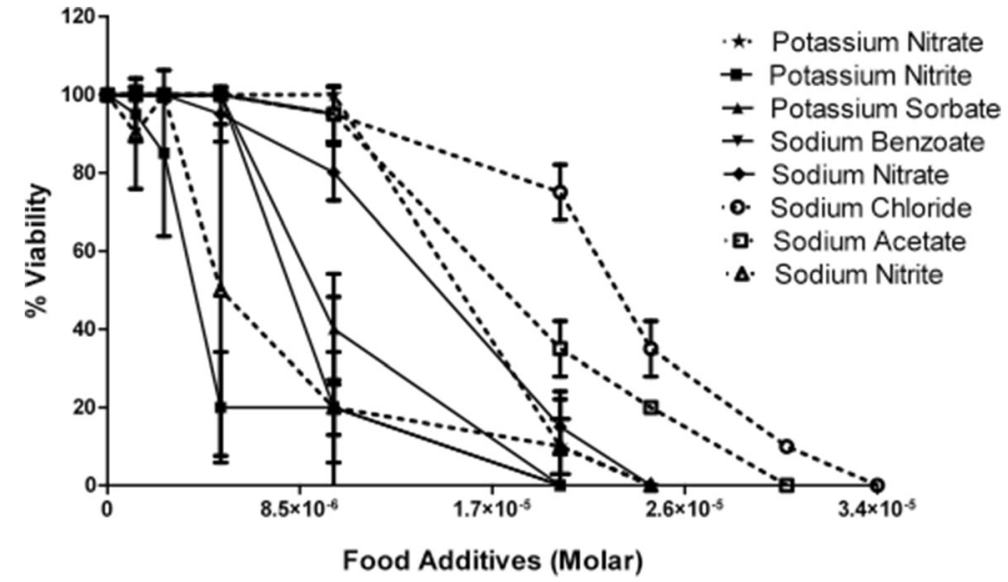




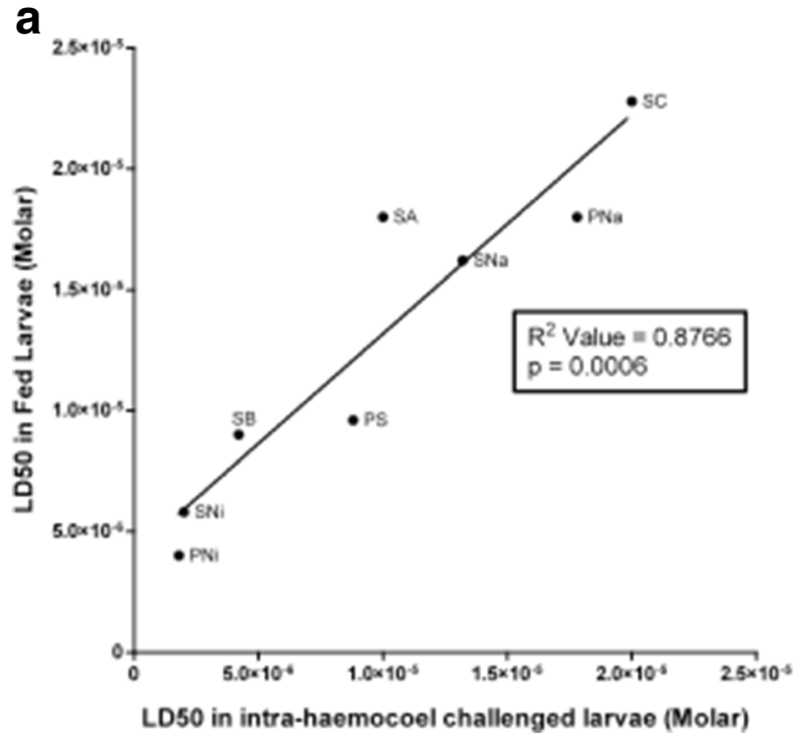

Fig. 3 Correlations between the $\mathrm{LD}_{50}$ (a) and $\mathrm{LD}_{80}(\mathbf{b})$ values of food preservatives when administered to Galleria mellonella larvae by feeding or by intra haemocoel injection. PNi potassium

feeding was plotted against the corresponding $\mathrm{LD}_{50}$ for the compounds obtained by feeding G. mellonella larvae. The resulting graph (Fig. 6) shows a positive correlation between the $\mathrm{LD}_{50}$ values obtained in both systems $\left(R^{2}=0.6506, p=0.0156\right)$.

\section{Discussion}

The many structural and functional similarities between the immune response of insects and the innate immune system of mammals (Browne et al. 2013) have b

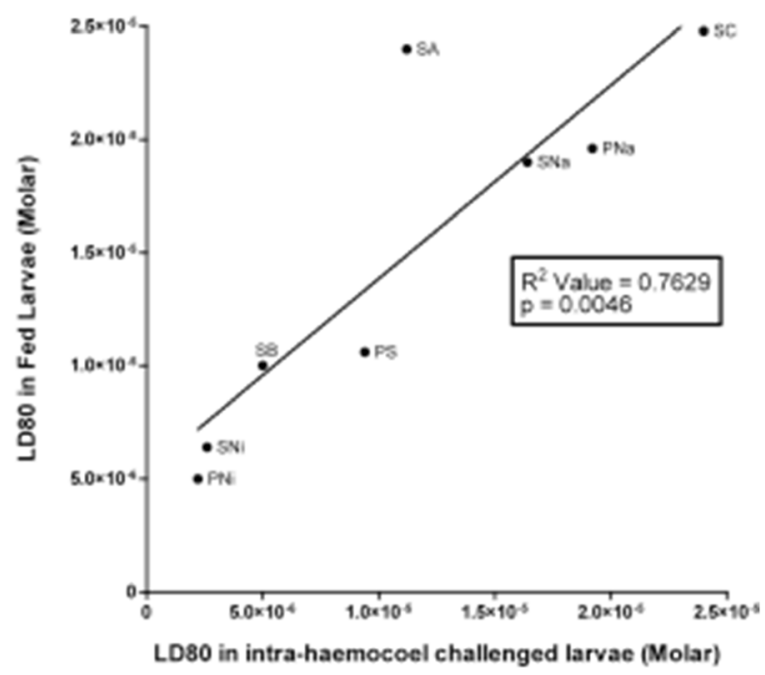

nitrite, $S N i$ sodium nitrite, $S B$ sodium benzoate, $P S$ potassium sorbate, $S A$ sodium acetate, $S N a$ sodium nitrate, $P N a$ potassium nitrate, $S C$ sodium chloride

been exploited to allow the use of insect as in vivo models for screening microbial pathogens and for measuring the efficacy of anti-microbial drugs. The similarities between the insect and the mammalian gastrointestinal and hepatic systems could also be exploited to allow the use of insects as models for measuring the relative toxicity of food preservatives and other food additives. $D$. melanogaster has been utilized to evaluate the toxicity of a wide range of products including pesticides (Arain et al. 2014), solvents (Soos and Szabad 2014) and nanoparticles (Carmona et al. 2015). The Drosophila wing spot test is a well-
Fig. 4 Effect of food preservatives on growth of HEp-2 cells. HEp-2 cells were exposed to different concentrations of food preservatives, and the effect on growth was quantified using an acid phosphatase assay. All values are the mean $\pm \mathrm{SE}$ of three independent determinations

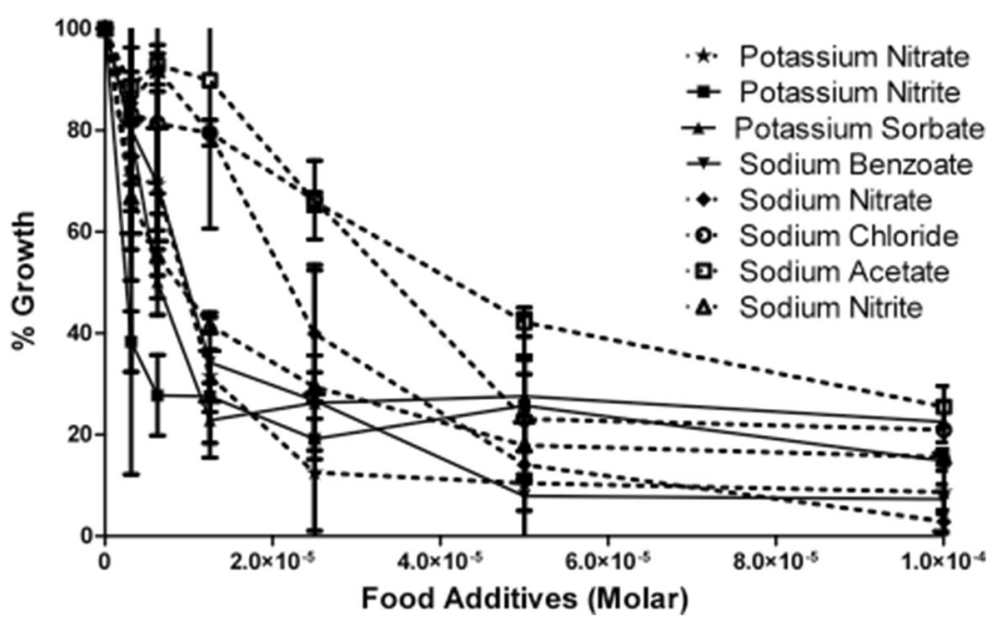




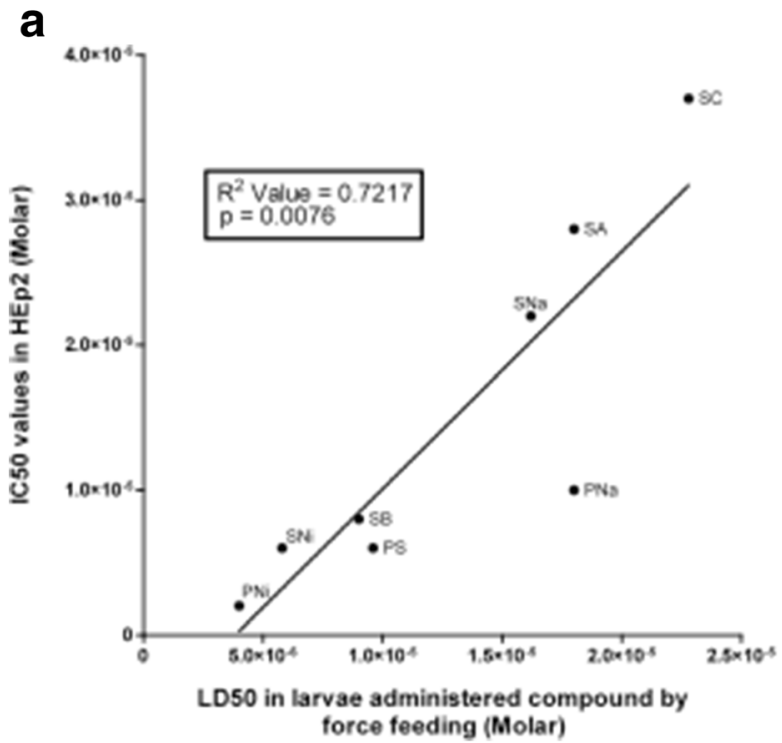

Fig. 5 Correlation between the $\mathrm{IC}_{50}$ values of food preservatives in HEp-2 cells and $\mathrm{LD}_{50}$ values of food preservatives when administered by feeding (a) or intra-haemocoel injection (b) to Galleria mellonella larvae. PNi potassium nitrite, SNi sodium

\section{b}

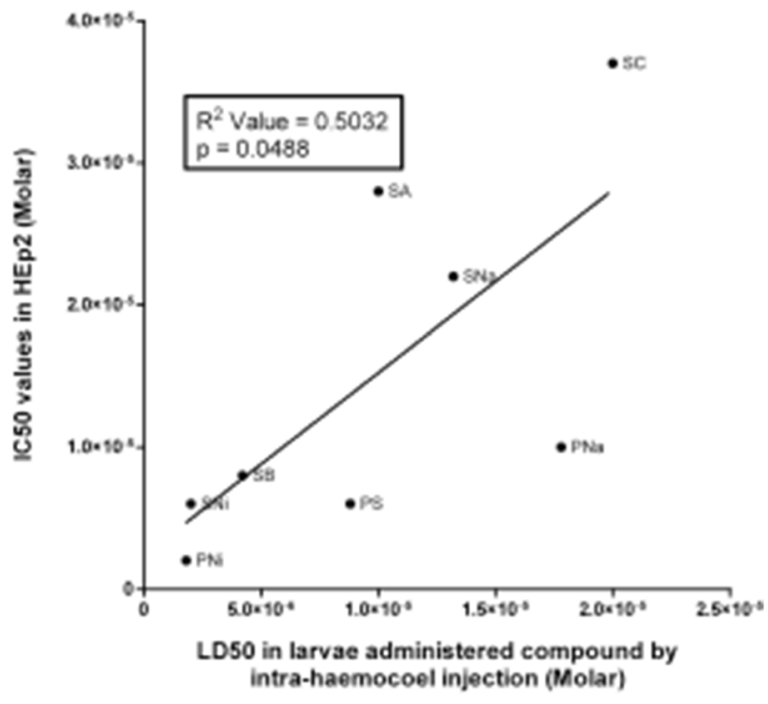

nitrite, $S B$ sodium benzoate, $P S$ potassium sorbate, $S A$ sodium acetate, $S N a$ sodium nitrate, $P N a$ potassium nitrate, $S C$ sodium chloride

2005). The red flour beetle (Tribolium castaneum) has been utilized to investigate the effect of the food contaminant acrylamide on fitness and survival (Grunwald et al. 2013) and demonstrated a correlation with results obtained using rats (Wang et al. 2010).
Fig. 6 Correlation between $\mathrm{LD}_{50}$ values of eight food preservatives when administered to rats and Galleria mellonella larvae by feeding. $P N i$ potassium nitrite, $S N i$ sodium nitrite, $S B$ sodium benzoate, $P S$ potassium sorbate, $S A$ sodium acetate, $S N a$ sodium nitrate, $P N a$ potassium nitrate, $S C$ sodium chloride

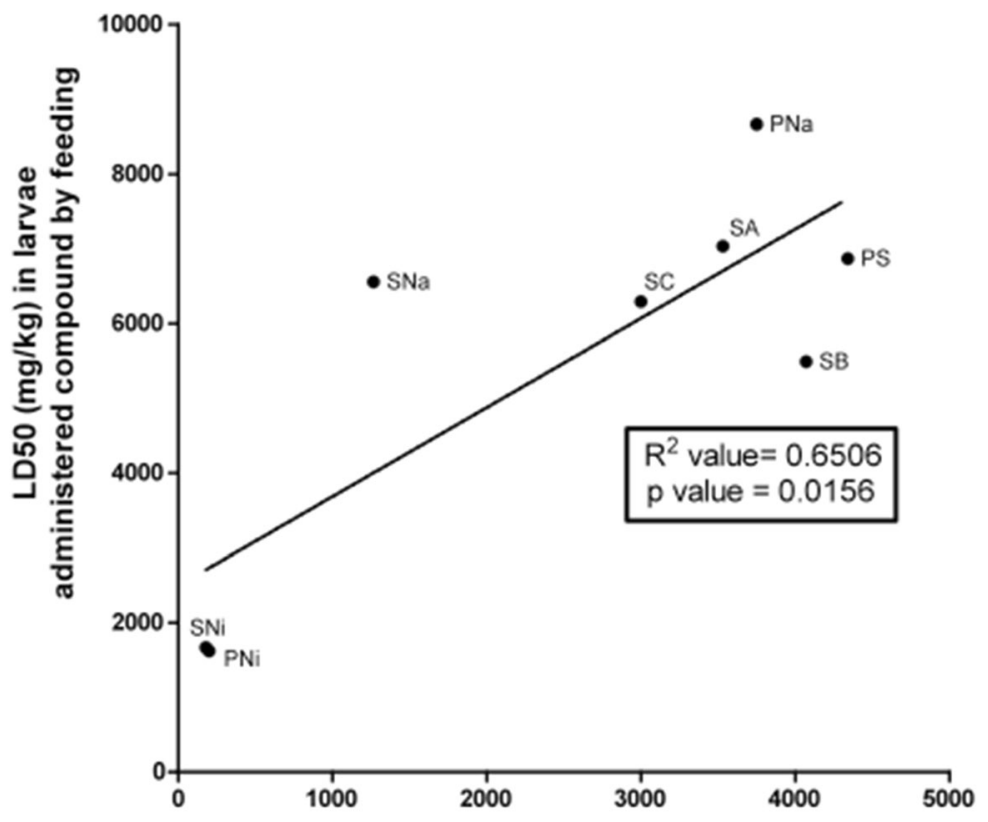

LD50 $(\mathrm{mg} / \mathrm{kg})$ in rats administered compound by feeding 
In the work presented here, G. mellonella larvae were administered doses of food preservative by force-feeding or by intra-haemocoel injection. The results demonstrated that the compounds were toxic irrespective of the route of administration, but the toxicity of the compounds was greatest when administered by direct injection into the haemocoel. The difference in the relative toxicity observed between the routes of administration may be explained by the structure of the insect digestive system. The insect foregut and hindgut are covered by cuticle, and the midgut epithelium is protected by the peritrophic membrane. Both the cuticle and the peritrophic membrane retard the entry of ingested microbes into the haemocoel (Vallet-Gely et al. 2008), and these structures may limit the entry of the food preservatives administered by the feeding route into the haemocoel and therefore reduce the relative toxicity.

The relative toxicity $\left(\mathrm{LD}_{50}\right)$ of the compounds in larvae is virtually identical by the different routes of administration. The only discrepancy is the relative toxicity of sodium nitrate and sodium acetate in larvae administered the compounds by feeding or by intrahaemocoel challenge. Strong positive correlations between the $\mathrm{LD}_{50}$ and $\mathrm{LD}_{80}$ values for each compound obtained by the different administration routes in larvae were established.

HEp-2 cells are widely used for screening the in vitro activity of anti-cancer drugs (Rossi et al. 2003) and have previously been employed to measure the relative toxicity of food additives (Stefanidou et al. 2003). The effect of the compounds on the growth of HEp-2 cells was determined, and a significant correlation between the effect of the compounds on the growth of HEp-2 cells and the response of larvae to the compounds was established. A strong correlation between the relative toxicity of the compounds is observed between HEp-2 cells and larvae force-fed or administered the compounds by intra-haemocoel challenge.

A positive correlation $\left(R^{2}=0.6506, p=0.0156\right)$ between the $\mathrm{LD}_{50}$ values obtained for the preservatives in rats and in G. mellonella larvae administered the compounds by feeding was established (Fig. 6).

In recent years, insects have been widely used as in vivo model systems (Cook and McArthur 2013) for studying the virulence of pathogens (Jacobsen 2014; Kavanagh and Fallon 2010), for assessing the activity of anti-fungal agents (Lionakis and Kontoyiannis 2005) and for assessing the efficacy and toxicity of novel antimicrobial drugs (Hamamoto et al. 2009; Rowan et al.
2009). The results presented here indicate that larvae of G. mellonella may be a useful model system for assessing the relative in vivo toxicity of food preservative agents and generate results that show a strong correlation to those that can be obtained using a cultured cell line or mammals. While an alternative system such as $G$. mellonella larvae will never replace the need to use mammals for evaluating the relative toxicity of food preservatives, their use may lead to a reduction in the number of mammals required for such testing and enables more the rapid testing of the toxicity of novel food preservatives.

\section{Compliance with ethical standards}

Financial disclosures The authors have no financial conflicts to disclose.

\section{References}

Ahamed M, Alhadlaq HA, Ahmad J, Siddique MA, Khan ST, Musarrat J, et al. Comparative cytotoxicity of dolomite nanoparticles in human larynx HEp2 and liver HepG2 cells. J Appl Toxicol. 2015;35(6):640-50.

Angelis D, Hoogenboom LAP, Huveneers-Oorsprong MBM, Zucco F, Stannati A. Established cell lines for safety assessment of food contaminants: differing furazolidone toxicity to V 79, HEp-2 and Caco-2 cells. Food Chem Toxicol. 1994;32(5):481-8.

Arain MS, Hu XX, Li GQ. Assessment of toxicity and potential risk of butene-fipronil using Drosophila melanogaster, in comparison to nine conventional insecticides. Bull Environ Contam Toxicol. 2014;92:190-5.

Browne N, Heelan M, Kavanagh K. An analysis of the structural and functional similarities of insect hemocytes and mammalian phagocytes. Virulence. 2013;4(7):597-603.

Buyukguzel E, Buyukguel K, Snela M, Erdem M, Radtke K, Ziemnicki K, et al. Effect of boric acid on antioxidant enzyme activity, lipid peroxidation, and ultrastructure of midgut and fat body of Galleria mellonella. Cell Biol Toxicol. 2013;29: $117-29$.

Carmona ER, Escobar B, Vales G, Marcos R. Genotoxic testing of titanium dioxide anatase nanoparticles using wing-spot test and the comet assay in Drosophila. Mutat Res. 2015;778:12-21.

Carocho M, Barreiro MF, Morales P, Ferreira CF. Adding molecules to food, pros and cons: a review on synthetic and natural food additives. Comp Rev Food Sci Food Saf. 2014;13:377-99.

Chamilos G, Samonis G, Kontoyiannis DP. Drosophila melanogaster as a model host for the study of microbial pathogenicity and the discovery of novel antimicrobial compounds. Curr Pharm Des. 2011;17(13):1246-3.

Chemistry MSDS, (2016). http://avogadro.chem.iastate.edu/MSDS/ 
Cook SM, McArthur JD. Developing Galleria mellonella as a model host for human pathogens. Virulence. 2013;4(5): 350-3.

Cotter G, Doyle S, Kavanagh K. Development of an insect model for the in vivo pathogenicity testing of yeasts. FEMS Immun Med Microbiol. 2000;27:163-9.

Desbois AP, Coote PJ. Utility of greater wax moth larva (Galleria mellonella) for evaluating the toxicity and efficacy of new antimicrobial agents. Adv Appl Microbiol. 2012;78:25-53.

Fallon J, Kelly J, Kavanagh K. Galleria mellonella as a model for fungal pathogenicity testing. Methods Mol Biol. 2012;845: 469-85.

Fallon JP, Reeves EP, Kavanagh K. The Aspergillus fumigatus toxin fumagillin suppresses the immune response of Galleria mellonella larvae by inhibiting the action of haemocytes. Microbiology. 2011;157:1481-8.

Fotakis G, Timbrell JA. In vitro cytotoxicity assays comparison of $\mathrm{LDH}$, neutral red, MTT and protein assay in hepatoma cell lines following exposure to cadmium chloride. Toxicol Lett. 2006;160:171-7.

Fuch BB, Eby J, Nobile CJ, EI Khoury JB, Mitchell AP, Mylonakis E. Role of filamentation in Galleria mellonella killing by Candida albicans. Microbes Infect. 2010;12:488-96.

Graf U, Singer D. Genotoxicity testing of promutagens in the wing somatic mutation and recombination test in Drosophila melanogaster. Rev Int Contam Ambient. 1992;8(1):15-27.

Grunwald S, Adam IV, Gurmai AM, Bauer L, Boll B, Wenzel U. The red flour beetle Tribolium castaneum as a model to monitor food safety and functionality. Adv Biochem Eng Biotechnol. 2013;135:111-22.

Hamamoto H, Tonoike A, Narushima K, Horie R, Sekimizu K. Silkworm as a model animal to evaluate drug candidate toxicity and metabolism. Biochem Physiol. 2009;149:334-9.

Jacobsen ID. Galleria mellonella as a model host to study virulence of Candida. Virulence. 2014;5(2):237-9.

Kavanagh K, Fallon J. Galleria mellonella larvae as models for studying fungal virulence. Fungal Biol Rev. 2010;24:79-83.

Kavanagh K, Reeves EP. Exploiting the potential of insects for invivo pathogenicity testing of microbial pathogens. FEMS Microbiol Rev. 2004;28(1):101-12.

Kelly J, Kavanagh K. Caspofungin primes the immune response of the larvae of Galleria mellonella and induces a nonspecific antimicrobial response. J Med Microb. 2011;60: 189-96.
Lionakis MS, Kontoyiannis DP. Fruit flies as a minihost model for studying drug activity and virulence in Aspergillus. Med Mycol. 2005;43:111-4.

Mukherjee K, Raju R, Fischer R, Vilcinskas A. Galleria mellonella as a model host to study gut microbe homeostasis and brain infection by the human pathogen Listeria monocytogenes. Adv Biochem Eng Biotechnol. 2013;135: $27-39$.

Mylonakis E, Morena R, El Khoury JB, Idnurm A, Heitman J, Calderwood SB, et al. Galleria mellonella as a model system to study Cryptococcus neoformans pathogenesis. Infect Immun. 2005;73:3842-50.

Pfizer (2007). Pfizer material data safety data sheet. Available at: http://www.pfizer.com/files/products/material_safety_data/ PZ00233.pdf

Rossi T, Castelli M, Zandomeneghi G, Ruberto A, Benassi L, Magnoni C, et al. Selectivity of action of glycyrrhizin derivatives on the growth of MCF-7 and HEp- 2 cells. Anticancer Res. 2003;23:3813-8.

Rowan R, Moran C, McCann M, Kavanagh K. Use of Galleria mellonella larvae to evaluate the in vivo anti-fungal activity of $\left[\mathrm{Ag}_{2}(\mathrm{mal})(\text { phen })_{3}\right]$. Biometals. 2009;22:461-7.

Sarikaya R, Cakir S. Genotoxicity testing of four food preservatives and their combinations in the Drosophila wing spot test. Environ Toxicol Pharmacol. 2005;20:424-30.

Scholar Chemistry (2009). Material data sheet potassium nitrite (MSDS \# 582.00). http://www.onboces.org/safety/msds/S/ Scholar\%20Chemical/Potassium_Nitrite_582.00.pdf

Soos I, Szabad J. Assaying benzene, a parquet varnish, and a synthetic thinner with respect to induction of in vivo chromosome loss in wing primordia cells of Drosophila. Mutation Res/Gen Toxicol Environ Muta. 2014;763:18-22.

Stefanidou M, Alevisopoulos G, Chatziioannou A, Koutselinis A. Assessing food additive toxicity using a cell model. Vet Hum Toxicol. 2003;45(2):103-5.

Vallet-Gely I, Lemaitre B, Boccard F. Bacterial strategies to overcome insect defences. Nature. 2008;6:302-13.

Wang H, Huang P, Tietao L, Jian L, Reinhold JH, Kui L, et al. Reproductive toxicity of acrylamide-treated male rats. Reprod Toxicol. 2010;29:225-30.

Yang TT, Sinai P, Kain SR. An acid phosphatase assay for quantifying the growth of adherent and non-adherent cells. Anal Biochem. 1996;241:103-8. 